\title{
Value judgment integration model for allocation in LCA
}

Rudy Patard

UMET, ECLi

Université de Lille

25 août 2016

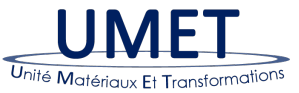




\section{Contents}

1. Introduction and context

1.1 Why LCA

1.2 What is doing LCA?

1.3 Is the methodology finished and OK?

1.4 Methodology under development

2. LCA a new model

2.1 Unified Theory of Allocation

2.2 Some correction proposal

2.3 Consequences

3. Summing-up results

4. Perspectives

5. Annexes 


\section{Table of Contents}

1. Introduction and context

1.1 Why LCA

1.2 What is doing LCA?

1.3 Is the methodology finished and OK?

1.4 Methodology under development

2. LCA a new model

2.1 Unified Theory of Allocation

2.2 Some correction proposal

2.3 Consequences

3. Summing-up results 


\section{Different impacts reports.}

Figure 1: Rebound principle, toward other life stages

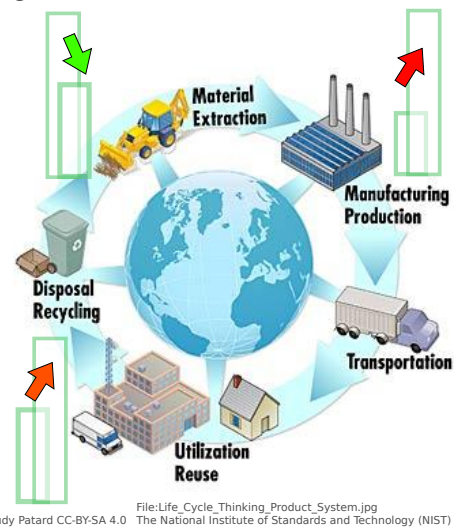

FIguRE 2: Rebound principle toward other nature of impacts.
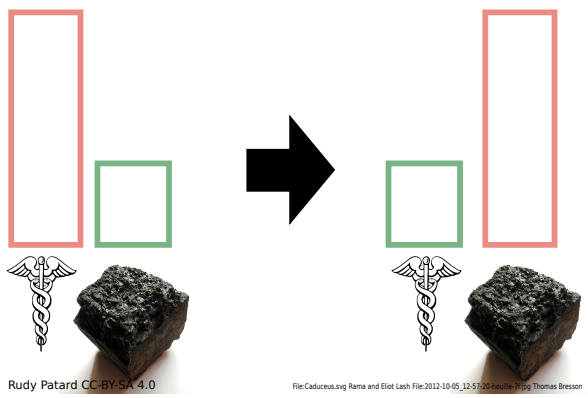

Large indicators sets ( $\tilde{1} 5$ in usual LCA methods, $\exists 200$ indicators in social LCA) clustered in 4 to 5 categories.

LCA aims at AVOIDING IMPACT REPORTS, without control, from one life cycle stage to another, from one indicator to another. 


\section{Schema global de l'Analyse en Cycle de Vie.}

Figure 3: Flows that count, a bit of LCA's vocabulary. ILCD Cycle modified [1].

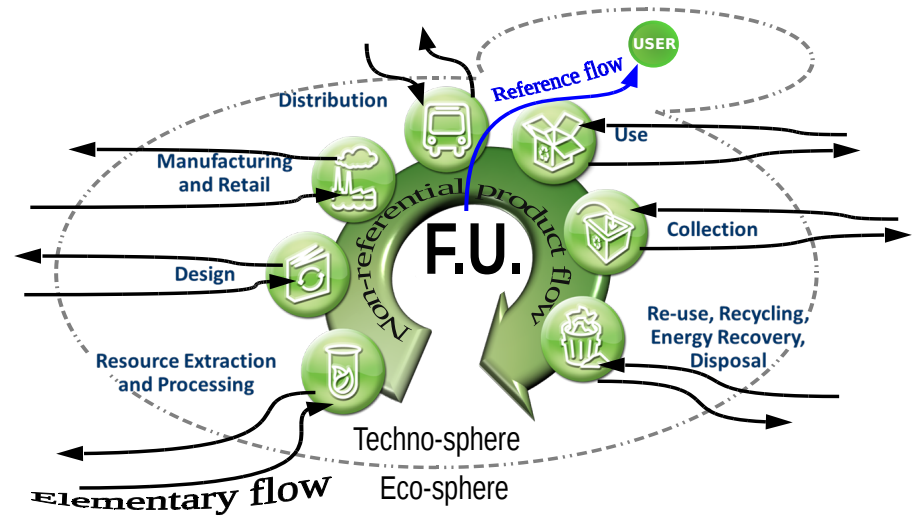

- LCA -> Comparison. the key = FunCtional Unit (F.U.)

- Ecosphere = no human intervention (before input flow, after ouput flow).

- $\sum$ elementary and products flow = INVENTORY (When multi-functionality is solved, no product remains.) 


\section{Impacts methods}

FiguRE 4: Different levels of information in LCA. From inventory to end-point [1, ILCD's guidance Fig. 15].

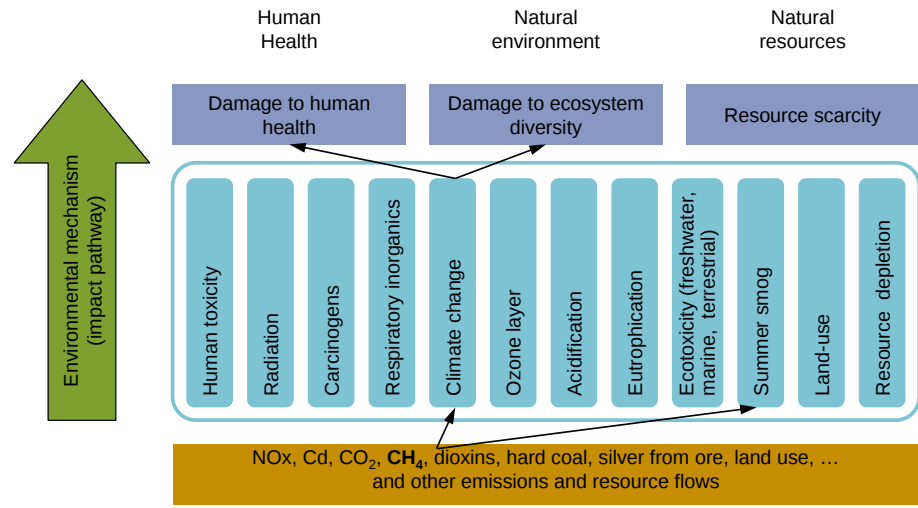

Area of Protection

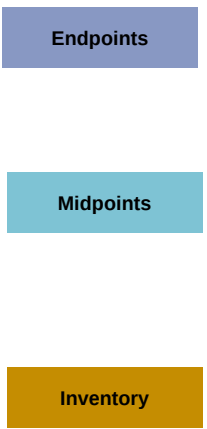




\section{LCA, a normalized framework}

Figure 5 : Normalized framework of LCA according to ILCD [1, Figure 1 p.1 Framework for life cycle assessment (from ISO $14040: 2006$; modified)].

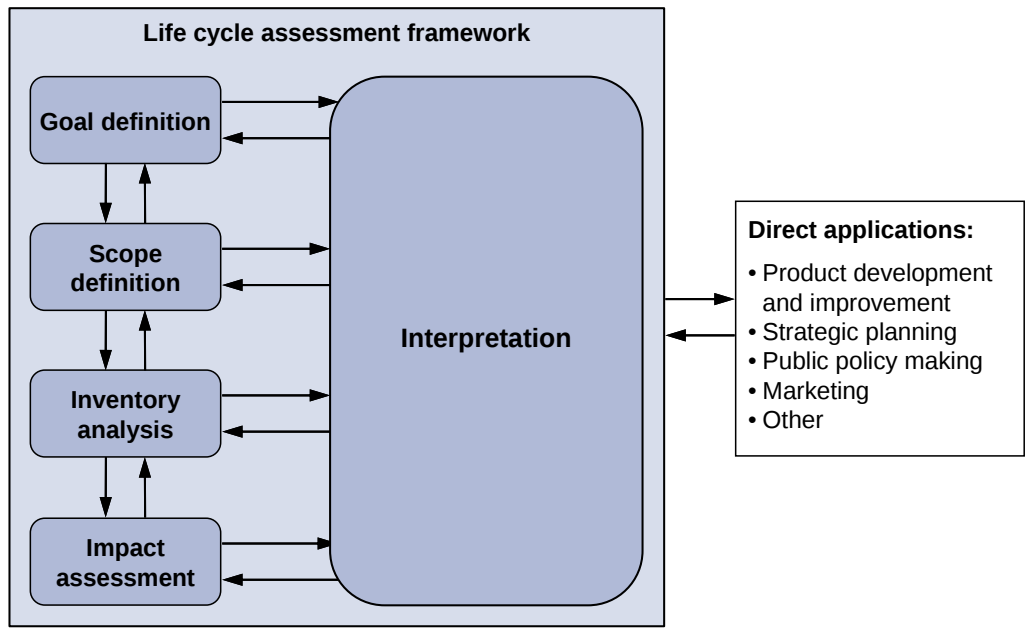




\section{Born in...}

Figure 6: Historical development of LCA and context. Expansion of Chen's work [2].

co-citation graph

Precursors

"began to brisk up"

"start of some awamess" "rapid development"
Chen's LCA's bibliometric investigation synthesis

Scarce historical link

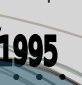

4 *Plausible "Environmental Repercussions and the Economic Structure: An Input-Output Approach"

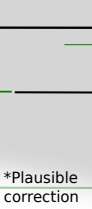

\section{Figure 7 : Decision support} interrogation

Table 2 Combination of two main aspects of the decision-context: decision orientation and kind of consequences in background system or other systems.

\begin{tabular}{|c|c|c|c|}
\hline \multirow{7}{*}{ 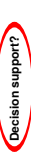 } & \multirow{4}{*}{ Yes } & \multicolumn{2}{|c|}{ Kind of process-changes in background system / other systems } \\
\hline & & None or small-scale & Large-scale \\
\hline & & Situation A & Situation B \\
\hline & & "Micro-level decision support" & "Meso/macro-level decision support" \\
\hline & & \multicolumn{2}{|c|}{ Situation C } \\
\hline & & \multicolumn{2}{|c|}{ "Accounting" } \\
\hline & & \multicolumn{2}{|c|}{$\begin{array}{l}\text { (with C1: including interactions with other systems, C2: excluding } \\
\text { interactions with other systems) }\end{array}$} \\
\hline
\end{tabular}

1st publication
of ISO standard $\quad \begin{aligned} & \text { ISO14040:2006 ILCD } \\ & \text { revision }\end{aligned}$

Standardisation march

- not recognising systematic decisional context

- insufficient cross-domain communication to solve complexity 


\section{Recognition of faillures leads to improvment}

\section{Has ISO 14040/44 Failed Its Role as a Standard for Life Cycle Assessment? Bo Weidema 2014}

"There is a different, but related, conflict in interpretation with respect to the allocation rules for recycling, both among practitioners and guidelines. [...] The difference in interpretation is related to-or at least amplified by-an ambiguity in ISO 14044."

Controversial and unspoken theme of... Values. "From behind the curtain : talking about values in LCA" Freidberg 2015 [4] 


\section{A criticised methodology, 15 unresolved problems}

\section{Ambiguity}

\section{+ Absence of value} judgement global integration

\section{$=$ Large scale issues, non-operational methodology and tools}

Figure 8: A survey of unresolved problems in life cycle assessment 2008 [5].

Table 1 LCA problems by phase

Phase Problem

Goal and scope definition

Functional unit definition ${ }^{a}$ Boundary selection ${ }^{a}$ Social and economic impacts ${ }^{a}$ Alternative scenario considerations ${ }^{a}$

Life cycle inventory analysis Allocation

Negligible contribution ('cutoff') criteria

Local technical uniqueness

Life cycle impact assessment Impact category and methodology selection Spatial variation

Local environmental uniqueness Dynamics of the environment Time horizons

Life cycle interpretation Weighting and valuation ${ }^{a}$ Uncertainty in the decision process All Data availability and quality

a One might reasonably consider these problems to be pivotal decisions. 


\section{Table of Contents}

\section{Introduction and context}

1.1 Why LCA

1.2 What is doing LCA?

1.3 Is the methodology finished and OK?

1.4 Methodology under development

2. LCA a new model

2.1 Unified Theory of Allocation

2.2 Some correction proposal

2.3 Consequences 


\section{What we see of an Ice-berg: Allocation, maths}

Unified Theory of Allocations and Constructs in Life Cycle Assessment and Input-Output Analysis, some of the formalism. Majeau-Bettez et al 2014 [6, eq. 11 eq. 38],

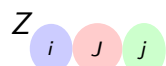

Commodity $i$ used in activity $J$ to produce commodity $j . U_{i}$ the use

of $\mathrm{i}$ for activity $\mathrm{J} ; V_{i J}$ the production (supply) of $\mathrm{i}$ by activity $\mathrm{J}$

$$
\begin{aligned}
& \underline{a}_{i J k}=u_{i j} \frac{\psi_{k J}}{\sum_{j \in \bullet} \psi_{j J} v_{j J}} \quad \text { (1) } \quad a_{i j k}=u_{i J} \sum_{n \in N} \frac{\psi_{n k J}}{\sum_{j \in \bullet} \psi_{n j J} v_{j J}} \operatorname{Pref}\left(\psi_{n j J / N}\right) \\
& \forall k \mid(k, J) \in \mathcal{J}, i \in \bullet, J \in *
\end{aligned}
$$

\section{Majeau-Bettez}

- $\psi_{k J}$ mono-criterion allocation

- implicit and absolute preference

$\operatorname{Pref}\left(\psi_{n j J / N}\right)$ could be expressed by geometric mean $p_{i}=\frac{\sqrt[n]{\prod_{j=1}^{n} A_{1 j}}}{\sum_{i=1}^{n} \sqrt[n]{\left(\prod_{j=1}^{n} A_{1 j}\right)}} 1$

1. Criticized by Saaty [7], 4 methods are shown in Ishizaka's work [8]. 


\section{Judgement matrix building. SAATY AHP}

FIGURE 9 : Pairwise comparison matrix principle, inspired by SAATY [9]

Pairwise Comparison
Capacity
Comparison

TABLE 1: The Fundamental scale of absolute numbers [9].

\begin{tabular}{ll}
\hline $\begin{array}{l}\text { Intensity of } \\
\text { Importance }\end{array}$ & Definition \\
\hline 1 & Equal importance \\
2 & Weak or slight \\
3 & Moderate importance \\
4 & Moderate plus \\
5 & Strong importance \\
6 & Strong plus \\
7 & Very strong or demons- \\
& trated importance \\
8 & Very, very strong \\
9 & Extreme importance \\
\hline
\end{tabular}

Reality scarcely enables us to be consistent. A Melchizedek or Midas of Champagne $(30 \mathrm{~L})$, crazy glasses I fit in.

\section{Axiological thinking is not simpler.}

Not limited to AHP. What matters : the 'consistence' between decision-maker's values and the used technique. 


\section{Allocation on heterogeneous objects}

Previous studies on multi-functionality treatment failed because mono-functional processes hardly exist :

Guinee, Calculating the influence of alternative allocation scenarios IN FOSSIL FUEL CHAINS [10] "[...] a common physical parameter cannot be determined or derived, and therefore economic allocation has been applied here again."

\begin{tabular}{||c||c|c|c||c|c|c||c||c||}
\hline \multicolumn{1}{||c||}{} & \multicolumn{2}{c||}{ PRODUCT 1 } & \multicolumn{2}{c||}{ PRODUCT 2 } & \multicolumn{2}{c||}{ SCALE AHP } \\
\hline TEST & EUR & KWH & KG & EUR & KWH & KG & PDT 1 SHARE & PDT 2 SHARE \\
\hline A & 2 & 6 & 15 & 8 & 7 & & $39,3 \%$ & $60,7 \%$ \\
B & & 102 & 56 & 24 & 15 & 33 & $21,3 \%$ & $78,7 \%$ \\
C & 13 & & 32 & 25 & 16 & 19 & $37,1 \%$ & $62,9 \%$ \\
D & 14 & 104 & & & 17 & 12 & $77,6 \%$ & $22,4 \%$ \\
E & 10 & 100 & 11 & 22 & & 27 & $37,1 \%$ & $62,9 \%$ \\
\hline DISSOCIATE & 10 & & 25 & & 13 & & $90,8 \%$ & $9,2 \%$ \\
\hline
\end{tabular}

So IT IS POSSIBLE TO ALLOCATE PRODUCTS WiTHOUT THEM TO SHARE THE SAME PROPERTIES OR FUNCTIONS (NOT FALLING IN 0\% - 100\% SHARES). 


\section{A new perception of waste and products}

Figure 10 : Co-treatment perspective, defining a new frontier for waste.

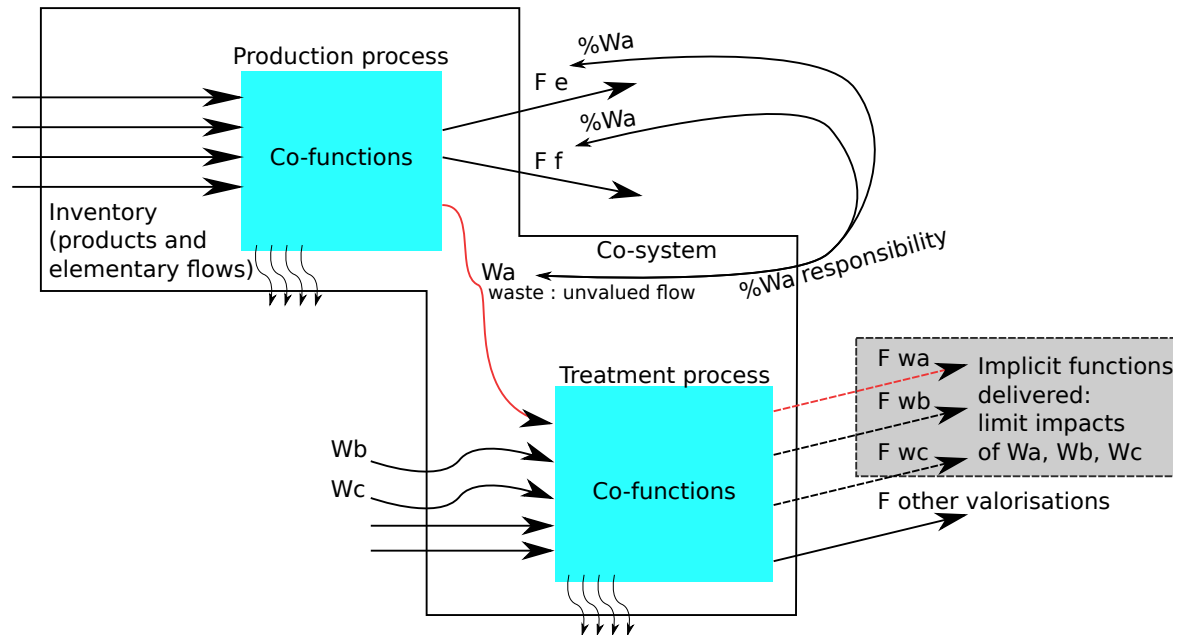


3. Summing-up results

\section{Table of Contents}

\section{Introduction and context}

1.1 Why LCA

1.2 What is doing LCA?

1.3 Is the methodology finished and OK?

1.4 Methodology under development

2. LCA a new model

2.1 Unified Theory of Allocation

2.2 Some correction proposal

2.3 Consequences

3. Summing-up results

4. Perspectives

5. Annexes 


\section{A new paradigm for values}

- Enables heterogeneous functions confrontation

- The value declaration step shall target all LCA's phase

- Key for LCA's legitimacy as a decision aiding tool providing value input is not confiscated to those submitted to consequences of the decision 


\section{Perspectives}

\section{Table of Contents}

\section{Introduction and context}

1.1 Why LCA

1.2 What is doing LCA?

1.3 Is the methodology finished and OK?

1.4 Methodology under development

2. LCA a new model

2.1 Unified Theory of Allocation

2.2 Some correction proposal

2.3 Consequences

3. Summing-up results

4. Perspectives

5. Annexes 


\section{On going of the LCA's methodology's correction}

Table 1 LCA problems by phase

\begin{tabular}{|c|c|}
\hline Phase & Problem \\
\hline Goal and scope definition & $\begin{array}{l}\text { Functional unit definition } \\
\text { Boundary selection }^{a} \\
\text { Social and economic impacts } \\
\text { Alternative scenario considerations }\end{array}$ \\
\hline Life cycle inventory analysis & $\begin{array}{l}\text { Allocation } \\
\text { Negligible contribution ('cutoff') } \\
\text { criteria } \\
\text { Local technical uniqueness }\end{array}$ \\
\hline Life cycle impact assessment & $\begin{array}{l}\text { Impact category and methodology } \\
\text { selection } \\
\text { Spatial variation } \\
\text { Local environmental uniqueness } \\
\text { Dynamics of the environment } \\
\text { Time horizons }\end{array}$ \\
\hline Life cycle interpretation & $\begin{array}{l}\text { Weighting and valuation } \\
\text { Uncertainty in the decision process }\end{array}$ \\
\hline All & Data availability and quality \\
\hline
\end{tabular}

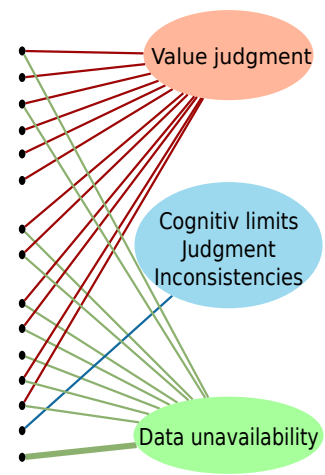

a One might reasonably consider these problems to be pivotal decisions.

- Develop explicit value judgement integration

- Operationalisation of the model to agent based modelling of LCA

- Building of a free-open wiki-based scientific journal Journal scientifique libre (wikiversity project). 


\section{Thank you for your attention}

rudy.patard@ed.univ-lille1.fr, rudy.patard@gmail.com Slides available on HAL archive (or soon).

Discussion on Wikiversity: Here 


\section{References I}

䓃国

European Commission, JRC Joint Research Centre, and Institute for Environment and Sustainability.

ILCD Handbook: General guide for Life Cycle Assessment - Detailed guidance.

Publications Office of the European Union

Haibin Chen, Yu Yang, Yan Yang, Wei Jiang, and Jingcheng Zhou.

A bibliometric investigation of life cycle assessment research in the web of science databases. pages 1-12.

00000 .

Bo Weidema.

Has ISO $14040 / 44$ failed its role as a standard for life cycle assessment?

18(3) : 324-326.

00000 .

Eusanne Freidberg.

From behind the curtain : talking about values in LCA

00000 .

John Reap, Felipe Roman, Scott Duncan, and Bert Bras.

A survey of unresolved problems in life cycle assessment : Part 1 : goal and scope and inventory analysis.

13(4) :290-300.

Euillaume Majeau-Bettez, Richard Wood, and Anders Hammer Strømman.

Unified theory of allocations and constructs in life cycle assessment and input-output analysis.

pages $n / a-n / a$

00002 .

Phomas L. Saaty

Making and validating complex decisions with the AHP/ANP.

14(1):1-36.

00050 . 


\section{Perspectives}

\section{References II}

Alessio Ishizaka and Markus Lusti.

How to derive priorities in AHP : a comparative study. 14(4) :387-400.

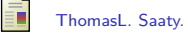

Decision making - the analytic hierarchy and network processes (AHP/ANP). 13(1) :1-35. 00323.

Deroen B. Guinée and Reinout Heijungs.

Calculating the influence of alternative allocation scenarios in fossil fuel chains. $12(3): 173-180$. 


\section{Table of Contents}

\section{Introduction and context}

1.1 Why LCA

1.2 What is doing LCA?

1.3 Is the methodology finished and OK?

1.4 Methodology under development

2. LCA a new model

2.1 Unified Theory of Allocation

2.2 Some correction proposal

2.3 Consequences

3. Summing-up results

4. Perspectives

5. Annexes 


\section{A new framework}

FigurE 11 : Schematic steps expansion to include processes and functions. Value (behind what is seen as functions) is not represented.

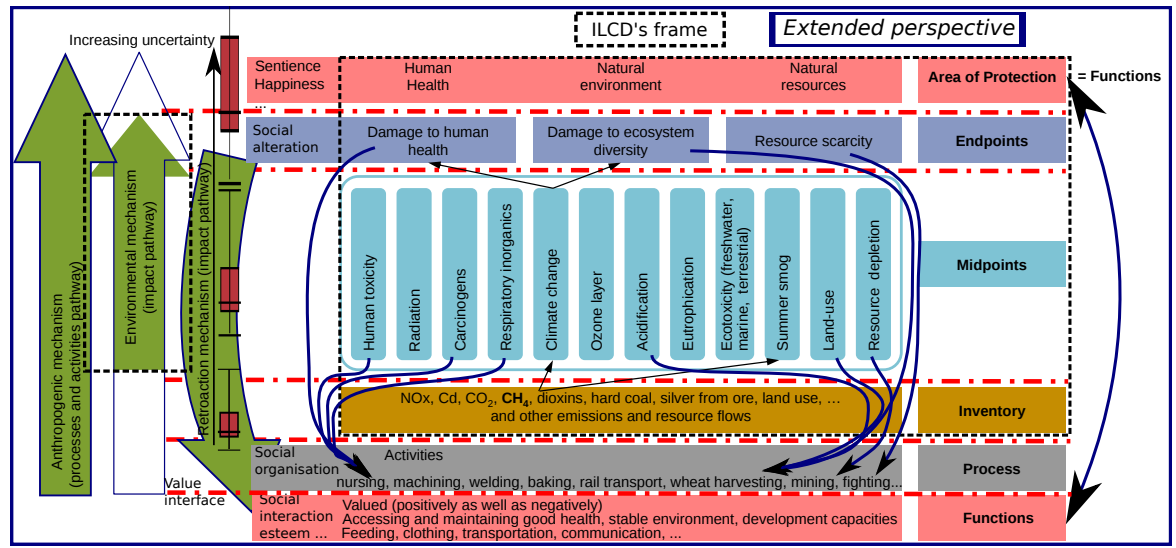

Life cycle impact assessment. Developped schematic steps from function to function crossing processes, inventory to category endpoints, (normalisation and weighting not shown).

This leads to agent based modelling. 


\section{Respectively a new standard}

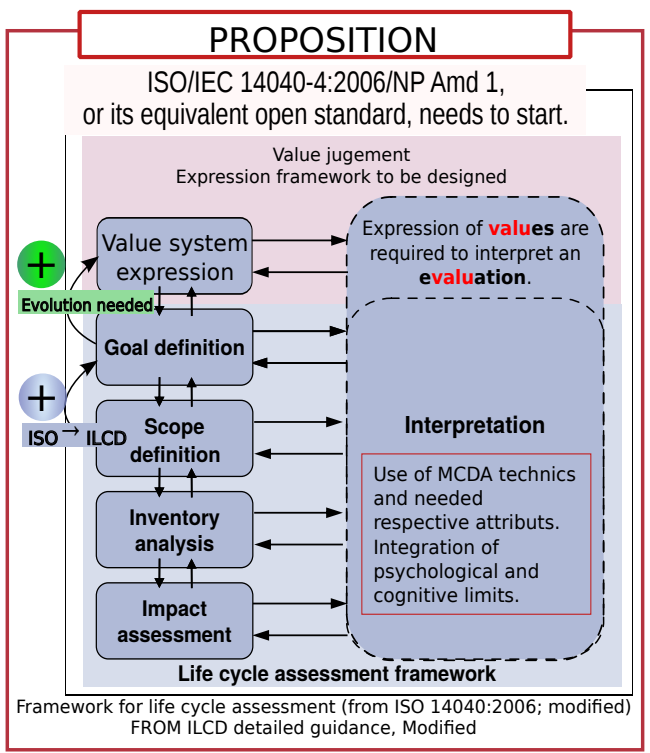




\section{Preferences and consistency, why not-Fuzzy AHP}

Consistency index :

For a matrix $\mathrm{A}\left(\mathrm{n} \mathrm{n}^{\mathrm{n}}\right)$ ( $\mathrm{n}$ attributes) one priority vector $P\left(p_{i}\right)$ could be given by ${ }^{a}$ :

$$
p_{i}=\frac{\sqrt[n]{\prod_{j=1}^{n} A_{1 j}}}{\sum_{i=1}^{n} \sqrt[n]{\left(\prod_{j=1}^{n} A_{1 j}\right)}}
$$

a. Criticized by Saaty [7], 4 derivation methods are shown in Ishizaka's work [8]

$$
\mathrm{Cl}=\sum_{1}^{n} \frac{A P_{i}}{P_{i}}
$$

The consistence ratio is determined by ratio between Consistency Indexes, one from the decision maker, the other random version of the same size.

Figure 12: Random index (RI) [9]

$$
C R=\frac{C l}{R l}
$$

\begin{tabular}{ccccccccccc}
\hline$n$ & 1 & 2 & 3 & 4 & 5 & 6 & 7 & 8 & 9 & 10 \\
\hline Random Index & 0 & 0 & .52 & .89 & 1.11 & 1.25 & 1.35 & 1.40 & 1.45 & 1.49 \\
\hline
\end{tabular}

Do not produce a consistent matrix out of an inconsistent one. Search for extension of the dimensions (classification and ontological issues generating the in-consistence). 


\section{The open-free journal protocol. Translation of a friend}

Figure 13: Principle of Journal Scientific Libre 我们为公共研究提出了一种全新的发布模式，一种自由的科学研究杂志。 我们这样做是为了避免在写作、阅读和审查中可能存在的任何瓶颈， 并利用集体的努力，来换取知识的聚集。

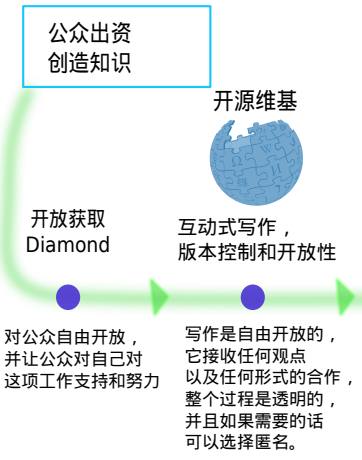

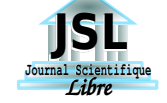

Bot 作者开源

\section{作者保护全透明的同行评议}

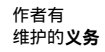

作者有 维护的义务

\section{确保一个开放的 科研工作环境， 并且对于其中 专业知识 可以有效地进行 批评和改正。}
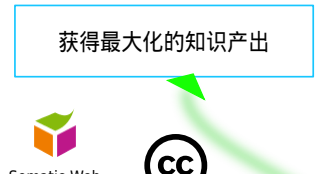

Sematic Web

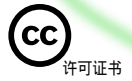

机器处理能力
CC, GPL, copyleft, BSD + 具体数据

（而不是简单地图表或趋势）

对于复杂的问题，自由开放的再利用 得益于现代化的计算机，和高效的能力。 检索结果的尺度 可以根据需要 自由的伸缩。 